\title{
Carboxyhemoglobin levels in medical intensive care patients: a retrospective, observational study
}

Andreas S Fazekas ${ }^{1,2}$, Marlene Wewalka ${ }^{3}$, Christian Zauner ${ }^{3}$ and Georg-Christian Funk ${ }^{1,2^{*}}$

\begin{abstract}
Introduction: Critical illness leads to increased endogenous production of carbon monoxide (CO) due to the induction of the stress-response enzyme, heme oxygenase-1 (HO-1). There is evidence for the cytoprotective and anti-inflammatory effects of CO based on animal studies. In critically ill patients after cardiothoracic surgery, low minimum and high maximum carboxyhemoglobin $(\mathrm{COHb})$ levels were shown to be associated with increased mortality, which suggests that there is an 'optimal range' for HO-1 activity. Our study aimed to test whether this relationship between $\mathrm{COHb}$ and outcome exists in non-surgical ICU patients.

Methods: We conducted a retrospective, observational study in a medical ICU at a university hospital in Vienna, Austria involving 868 critically ill patients. No interventions were undertaken. Arterial $\mathrm{COHb}$ was measured on admission and during the course of treatment in the ICU. The association between arterial COHb levels and ICU mortality was evaluated using bivariate tests and a logistic regression model.

Results: Minimum COHb levels were slightly lower in non-survivors compared to survivors $(0.9 \%, 0.7 \%$ to $1.2 \%$ versus $1.2 \%, 0.9 \%$ to $1.5 \% ; P=0.0001$ ), and the average $\mathrm{COHb}$ levels were marginally lower in non-survivors compared to survivors $(1.5 \%, 1.2 \%$ to $1.8 \%$ versus $1.6 \%, 1.4 \%$ to $1.9 \%, P=0.003)$. The multivariate logistic regression analysis revealed that the association between a low minimum $\mathrm{COHb}$ level and increased mortality was independent of the severity of illness and the type of organ failure.

Conclusions: Critically ill patients surviving the admission to a medical ICU had slightly higher minimum and marginally higher average $\mathrm{COHb}$ levels when compared to non-survivors. Even though the observed differences are statistically significant, the minute margins would not qualify $\mathrm{COHb}$ as a predictive marker for ICU mortality.
\end{abstract}

\section{Introduction}

$\mathrm{CO}$ is synthesized naturally in the body and serves a range of physiological functions including vasodilation, angiogenesis, vascular remodeling, protection against tissue damage and modulation of the inflammatory response [1,2]. Approximately $85 \%$ of the $\mathrm{CO}$ is produced by heme oxygenase ( $\mathrm{HO}$ ), which catalyses heme to $\mathrm{CO}$, iron and biliverdin. Biliverdin is further broken down into bilirubin [3]. The major site of heme catabolism, and thus CO production, is the liver [4]. The normal blood $\mathrm{COHb}$ saturation in non-smokers is approximately $1 \%$ [5], the mean saturation in smokers of approximately 20 cigarettes per day lies around 5.5\% [6]. The majority of $\mathrm{CO}$ is removed from the body via

\footnotetext{
* Correspondence: georg-christian.funk@meduniwien.ac.at 'Department of Respiratory and Critical Care Medicine, Otto Wagner Hospital, Sanatoriumstrasse 2, A-1140 Vienna, Austria

Full list of author information is available at the end of the article
}

expiration [7]. Of the two isoforms of heme oxygenase (HO-1, HO-2), HO-1 is the only inducible isoform [8]; it is induced by oxidative stress, hypoxia, heavy metals, sodium arsenite, heme and heme derivatives, as well as by cytokines [9-11].

Increased expression of $\mathrm{HO}-1$ and elevated $\mathrm{COHb}$ levels have been demonstrated in patients with critical disease, chronic obstructive pulmonary disease (COPD), systemic inflammatory response syndrome and acute respiratory distress syndrome [12-14]. HO-1 induction may be beneficial because its products possess antiinflammatory and antioxidant properties $[15,16]$. However, excessive HO-1 activity is deleterious, possibly due to the liberation of molecular iron [17]. Melley et al. observed that patients who were admitted to an ICU following cardiothoracic surgery were more likely to die in the ICU if they had lower minimum or higher maximum $\mathrm{COHb}$ levels [18], thus supporting the hypothesis

\section{() Biomed Central}

(c) 2012 Fazekas et al.; licensee BioMed Central Ltd. This is an open access article distributed under the terms of the Creative Commons Attribution License (http://creativecommons.org/licenses/by/2.0), which permits unrestricted use, distribution, and reproduction in any medium, provided the original work is properly cited. 
that there is an optimal range for HO-1 induction [17]. Of interest, inhaled $\mathrm{CO}$ is also currently being tested as a therapeutic agent based on evidence of cytoprotective and anti-inflammatory effects from animal studies. The observed peak levels of $\mathrm{COHb}$ in these preclinical studies typically range from $5 \%$ to $30 \%$ [19]. However, the therapeutic potential of $\mathrm{CO}$ in humans is limited by its toxicity. For example, even low levels of $2 \%$ to $6 \%$ $\mathrm{COHb}$ decrease exercise time to angina or produce an increase in arrhythmias in non-smoking patients with known coronary artery disease $[20,21]$. On the other hand, healthy volunteers have been shown to tolerate levels of $12 \%$ to $14 \%$ without serious side effects [19].

We proposed the following hypothesis for our study: because abnormal $\mathrm{COHb}$ levels correlate with an increased ICU mortality in critically ill medical patients, $\mathrm{COHb}$ would serve as a predictive marker for ICU mortality. In addition, detailed knowledge about the characteristics of $\mathrm{COHb}$ levels in critically ill patients would be of use for experimental studies involving $\mathrm{CO}$ as a therapeutic agent.

\section{Materials and methods \\ Study population}

The study was observational and retrospective in nature. All non-surgical patients who were consecutively admitted to one of the ICUs of the General Hospital of Vienna between December 3, 2001 and September 26, 2005 were considered for inclusion. Because no additional interventions were undertaken and analysis was performed on anonymous data, the need for informed consent was waived. The local ethics committee approved the study. The exclusion criteria included previous admissions to the ICU, planned withdrawal of therapy within 24 hours, and a surgical cause for admission.

\section{Data collection}

Results from point of care analyzers for every patient who was admitted to the ICU were automatically downloaded into a computerized clinical information system. Collected data were manually checked for accuracy and were linked to the patients' medical record numbers. The admitting physician manually recorded the reason for admission in the patient files. Patients were assigned to a distinct admission category based on the recorded reason for admission [22].

\section{Laboratory assays}

$\mathrm{COHb}$ levels were determined immediately upon ICU admission and every four to six hours thereafter using a heparinized blood sample that was collected from an indwelling arterial catheter. The point of care analyzer runs a zero calibration of the optical system against a colorless calibration fluid at least every four hours to guarantee accuracy.

\section{Severity of illness and ICU outcome}

Severity of illness was assessed by the Simplified Acute Physiology Score II (SAPS II) [23]. Scoring was performed on the worst values that were recorded in the 24 hours following admission to the ICU using the data retrieved from the computerized clinical information system. The outcome variables measured included ICU mortality and ICU length of stay. Furthermore, the presence of organ failure in the respiratory, circulatory, renal, hepatic, and cerebral system was recorded based on Sepsis-related Organ Failure Assessment (SOFA) criteria [24].

\section{Data analysis}

Data are presented as median and interquartile ranges or as mean and standard deviation. Minimum, maximum, average and area under the curve values as well as the variance for measured $\mathrm{COHb}$ levels were calculated according to the Melley study [18]. Statistical tests and mathematical modeling were performed using PASW v18. Correlation in normally distributed variables was calculated by Pearson's coefficient. Multivariate logistic regression was performed using the vital status upon ICU discharge as the response variable and the $\mathrm{COHb}$ level as the primary exposure variable. Predefined confounding variables were included in the initial regression model, including the SAPS II score, the admission category, the presence and type of organ failure, and the age and gender of the patients. Models were subsequently refined by backward exclusion.

To compare serial $\mathrm{COHb}$ measurements according to ICU survival, we used a generalized estimating equation assuming a first order exponential correlation matrix for repeated observations within one patient.

For all analyses statistical significance was defined by a two-sided $P<0.05$.

\section{Results}

\section{Admission characteristics}

The study flow chart is presented in Figure 1. A total of 1,416 patients (1,483 admissions) were admitted to the ICU during the 46-month study period. The analysis was restricted to the first admission for the 67 patients with multiple ICU admissions; 481 patients were excluded from the analysis (Figure 1).

The causes of admission and the types of organ failure in the remaining 868 patients are shown in Table 1. There were $525(60 \%)$ male patients, and the median age of the patients was 59 years old (47 to 70 ). The median SAPS II score was 49 (34 to 62). The median length of ICU stay was 6 days (3 to 11), and 220 


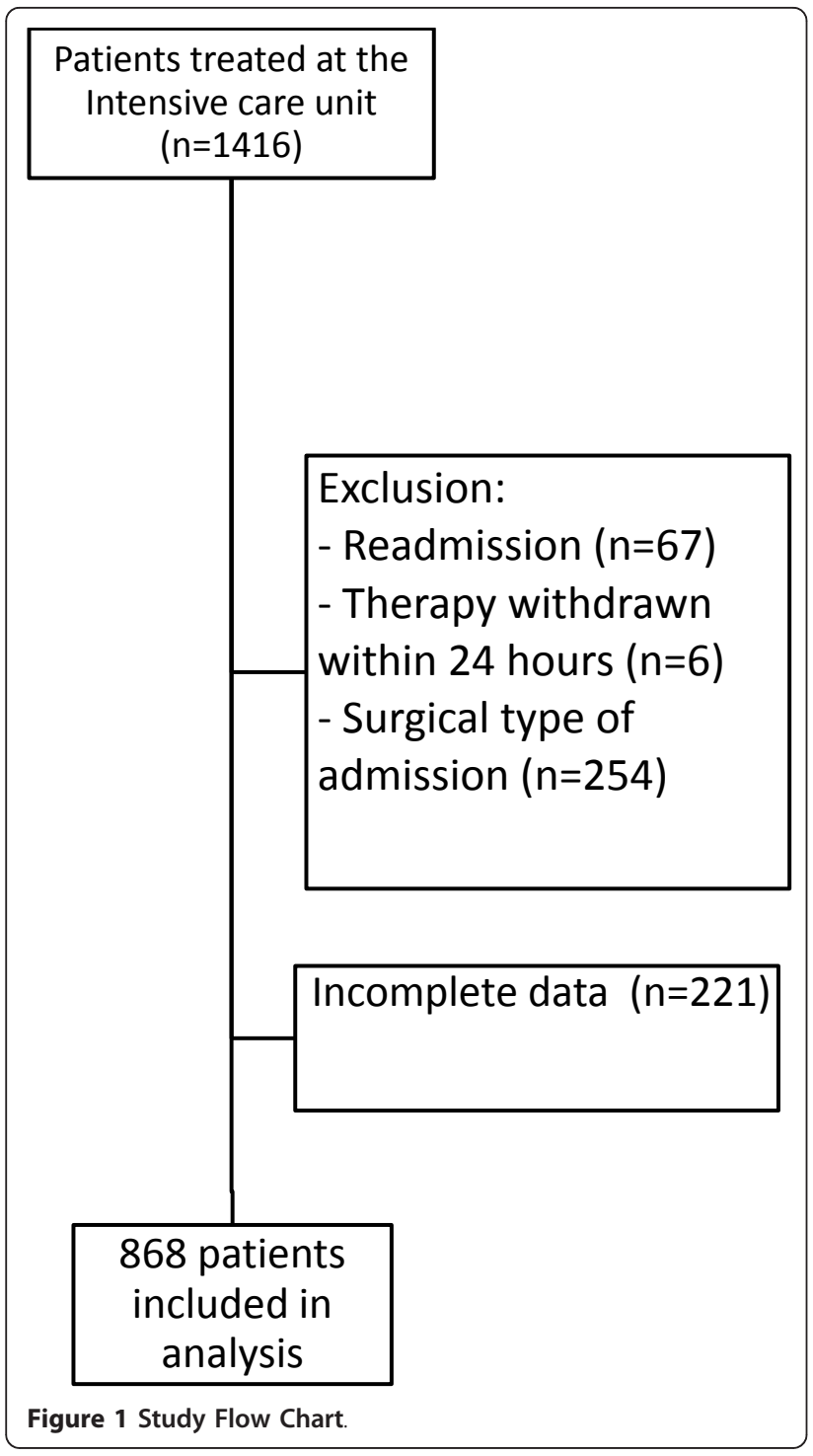

patients (25\%) died in the ICU. SAPS II scores were significantly higher in the group of non-survivors. There was no difference in age between the two patient groups. Circulatory, renal, hepatic, and cerebral failure was significantly and independently associated with ICU mortality, whereas respiratory failure did not show a correlation (Table 2).

\section{$\mathrm{COHb}$ levels in the entire cohort}

The mean $\mathrm{COHb}$ level in all patients was $1.6 \%$ (1.3\% to $1.9 \%)$, which was elevated compared to healthy nonsmokers (approximately $0.8 \%$ ) but considerably less than the $\mathrm{COHb}$ levels in current smokers (approximately 6\% to $8 \%$ ) [5]. The minimum and maximum $\mathrm{COHb}$ levels were $1.1 \%(0.8 \%$ to $1.4 \%)$ and $2.1 \%$ ( $1.7 \%$ to $2.6 \%)$, respectively, in each patient. The complete
Table 1 Admission category and organ failure on admission in the entire cohort.

\begin{tabular}{lll}
\hline Admission Category & Number & Percent (\%) \\
\hline Metabolic disease & 4 & 0 \\
Respiratory disease & 234 & 27 \\
Cardiovascular disease & 204 & 24 \\
Shock & 6 & 1 \\
Renal disease & 23 & 3 \\
Neurologic disease & 74 & 9 \\
Sepsis & 80 & 9 \\
Trauma (not operated) & 3 & 0 \\
Gastrointestinal disease & 109 & 13 \\
Hematologic disease & 20 & 2 \\
Medical, not otherwise specified & 108 & 12 \\
Pregnancy & 3 & 0 \\
Organ Failure on admission & & \\
Respiratory & 638 & 74 \\
Circulatory & 454 & 52 \\
Renal & 270 & 31 \\
Hepatic & 204 & 24 \\
Cerebral & 373 & 43 \\
\hline
\end{tabular}

Organ failure was defined according to SOFA criteria [24]

characteristics of the $\mathrm{COHb}$ levels including the variance and area under the curve results are shown in Table 3.

\section{$\mathrm{COHb}$ levels according to admission category and severity of illness}

Mean $\mathrm{COHb}$ differed between admission categories (Figure 2). Highest values were observed in patients with renal and gastrointestinal disease. Lowest levels were seen in the neurological and medical (not otherwise specified) categories.

Minimal $\mathrm{COHb}$ was inversely correlated with SAPS II score (Pearson's correlation coefficient with 95\% confidence intervals: 0.21 (0.14 to 0.27$), P<0.0001$ ) (Figure 3 ). Therefore, patients who were severely ill on admission had lower minimal levels of $\mathrm{COHb}$ during the course of their treatment in the ICU.

\section{$\mathrm{COHb}$ levels andmortality}

The non-survivors had a slightly lower minimum $\mathrm{COHb}$ level compared to the survivors $(0.9 \%, 0.7 \%$ to $1.2 \%$ versus $1.2 \%, 0.9 \%$ to $1.5 \% ; P=0.0001)$; therefore, the patients who died had the lowest $\mathrm{COHb}$ levels. In addition, the mean $\mathrm{COHb}$ level was marginally lower in the non-survivors $(1.5 \%, 1.2 \%$ to $1.8 \%$ versus $1.6 \%, 1.4 \%$ to $1.9 \% ; P=0.003)$. During the first 72 hours after ICU admission average $\mathrm{COHb}$ was $0.1 \%$ lower in patients who died compared to patients who survived; $P=0.003$. Differences were most pronounced during the first 48 hours (Figure 4). 
Table 2 Admission category and organ failure according to the survival status.

\begin{tabular}{|c|c|c|c|c|c|c|}
\hline & & \multicolumn{2}{|c|}{ ICU survivors $(n=648)$} & \multicolumn{2}{|c|}{ ICU non-survivors $(n=220)$} & \\
\hline & & Number & $\%$ & Number & $\%$ & \\
\hline \multirow[t]{13}{*}{ Admission Category } & Metabolic disease & 4 & 1 & 0 & 0 & \\
\hline & Respiratory disease & 196 & 30 & 38 & 17 & \\
\hline & Cardiovascular disease & 155 & 24 & 49 & 22 & \\
\hline & Shock & 2 & 0 & 4 & 2 & \\
\hline & Renal disease & 21 & 3 & 2 & 1 & \\
\hline & Neurologic disease & 61 & 9 & 13 & 6 & \\
\hline & Sepsis & 44 & 7 & 36 & 16 & \\
\hline & Trauma (not operated) & 2 & 0 & 1 & 0 & \\
\hline & Gastrointestinal disease & 75 & 12 & 34 & 15 & \\
\hline & Hematologic disease & 14 & 2 & 6 & 3 & \\
\hline & Medical, not otherwise specified & 71 & 11 & 37 & 17 & \\
\hline & Pregnancy & 3 & 0 & 0 & 0 & \\
\hline & & & & & & $P$-value \\
\hline \multirow[t]{5}{*}{ Organ Failure } & Respiratory & 472 & 73 & 166 & 75 & 0.45 \\
\hline & Circulatory & 290 & 45 & 164 & 75 & 0.0001 \\
\hline & Renal & 158 & 24 & 112 & 51 & 0.0001 \\
\hline & Hepatic & 124 & 19 & 80 & 36 & 0.0001 \\
\hline & Cerebral & 265 & 41 & 108 & 49 & 0.034 \\
\hline
\end{tabular}

Table $3 \mathrm{COHb}$ in the entire cohort, values expressed as \% of total hemoglobin

\begin{tabular}{llllll}
\hline & Mean & Standard-deviation & Median & Percentile 25 & Percentile 75 \\
\hline COHb minimum & 1.1 & 0.5 & 1.1 & 0.8 & 1.4 \\
COHb maximum & 2.2 & 0.8 & 2.1 & 1.7 & 2.6 \\
COHb mean & 1.6 & 0.5 & 1.6 & 1.3 & 1.9 \\
COHb variance & 0.1 & 0.3 & 1.6 & 0 & 0.1 \\
COHb area under curve & 1.6 & 0.5 & 1.3 & 1.9 \\
\hline
\end{tabular}

AUC, area under the curve.

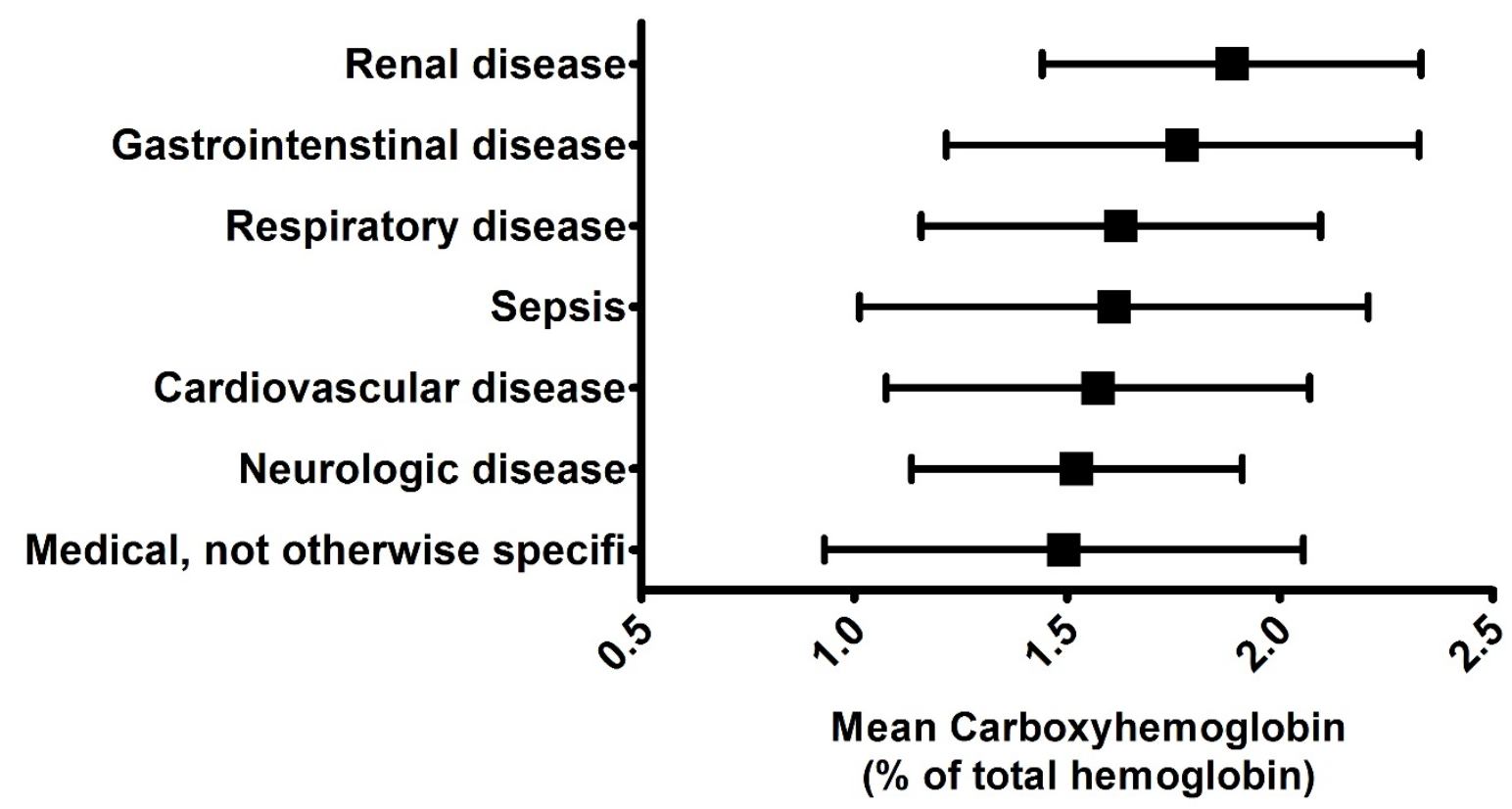

Figure 2 Mean carboxyhemoglobin during the stay on the ICU according to the admission category. $P<0.0001$ in univariate ANOVA. 
The maximum $\mathrm{COHb}$ level did not differ between the two groups (survivors $2.1 \%, 1.7 \%$ to $2.6 \%$ versus nonsurvivors $2.1 \%, 1.5 \%$ to $2.5 \% ; P=0.19$ ). The $\mathrm{COHb}$ variance was marginally smaller in the survivors compared to the non-survivors $(0.0 \%, 0.0$ to $0.1 \%$ versus $0.1 \%, 0.0$ to $0.1 \% ; P=0.0001)$. The $\mathrm{COHb}$ area under the curve results were marginally higher in the survivors compared to the non-survivors $(1.6 \%, 1.4 \%$ to $1.9 \%$ versus $1.5 \%, 1.2 \%$ to $1.8 \% ; P=0.01$ ).

The association between a low minimum $\mathrm{COHb}$ level and increased mortality was independent of the severity of illness and the type of organ failure on ICU admission. The results of the multivariate logistic regression are shown in Table 4.

\section{Discussion}

Our study shows that the minimum and average $\mathrm{COHb}$ levels are marginally higher in medical patients who survive an episode of critical illness compared to nonsurvivors. The study by Melley et al. showed that the minimum $\mathrm{COHb}$ level was significantly higher in patients who survived a short ICU stay (median $1.0(0.9$ to 2.8) days) following cardiothoracic surgery compared to patients who died in the ICU [18]. This association was reproduced in our patient cohort of general medical patients who required longer ICU stays (median 6 (3 to 11) days). Furthermore, the maximum $\mathrm{COHb}$ level was associated with an increased mortality in the Melley study $(P<0.001$ in univariate analysis and $P=0.08$ in multivariate analysis); however, this association was not reproduced in our study.

Our study also shows differences in $\mathrm{COHb}$ levels according to admission category with patients admitted with renal and gastrointestinal disease having the highest levels. However, further data would be needed to draw pathophysiological conclusions from

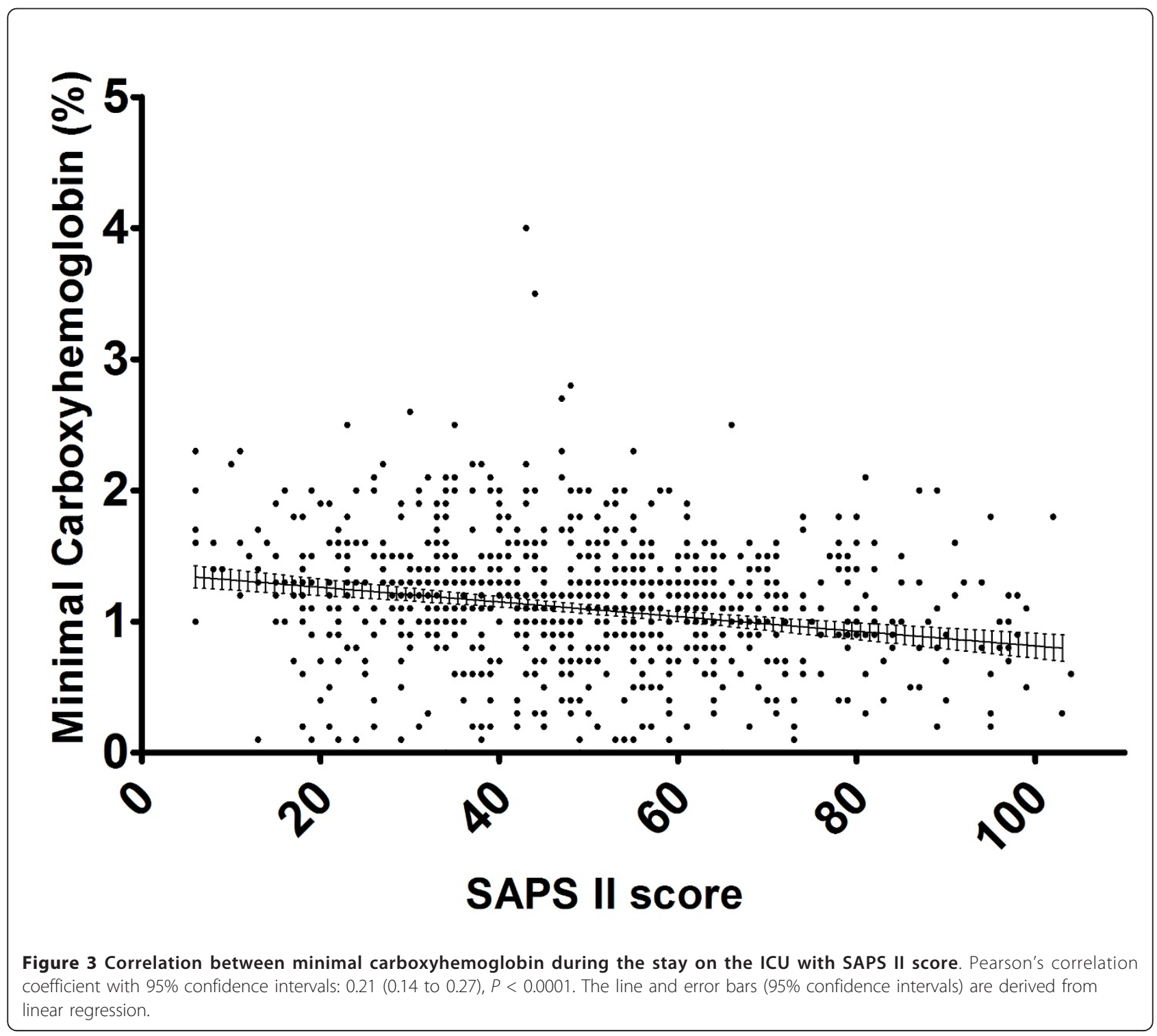




\section{$\Delta$ Survivors \\ $\nabla$ Non-Survivors}

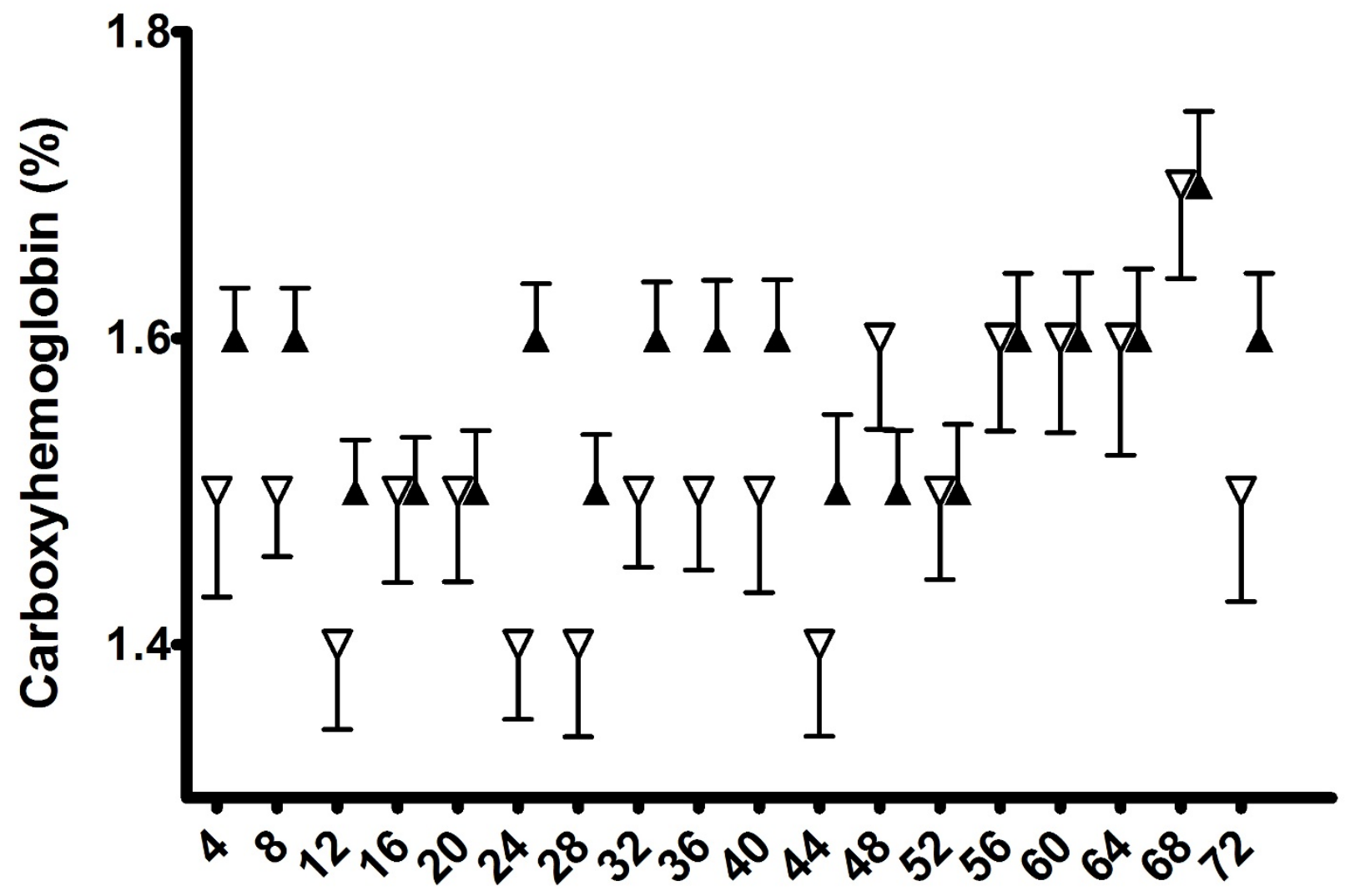

Hours after ICU admission

Figure 4 Mean levels of $\mathrm{COHb}$ during the first $\mathbf{7 2}$ hours after admission to the ICU. Empty and full triangles represent non-survivors and survivors, respectively. In order to prevent overlap black triangles were shifted to the right by 1.2 hours.

this observation. The expected correlation between SAPS II score and COHb level was seen in our study with sicker patients having lower minimal $\mathrm{COHb}$ levels.
The strengths of our study include the enrollment of a large patient cohort and being the first study to analyze $\mathrm{COHb}$ levels in non-surgical patients who were admitted to a general medical ICU. The limitations of

Table 4 Logistic regression analysis of the association between minimal COHb level and ICU mortality

\begin{tabular}{lll}
\hline & Odds ratio and 95\% confidence intervals & $P$-value \\
\hline COHb minimum, \% & $0.6(0.4$ to 0.8$)$ & 0.001 \\
SAPSII score & $1.0(1.0$ to 1.0$)$ & $<0.001$ \\
Cardiovascular failure on ICU admission, yes/no & $2.2(1.6$ to 3.3$)$ & $<0.001$ \\
Renal failure on ICU admission, yes/no & $1.8(1.2$ to 2.6$)$ & 0.003 \\
Hepatic failure on ICU admission, yes/no & $1.8(1.2$ to 2.7$)$ & 0.003 \\
\hline
\end{tabular}

SAPS II score and the type of organ failure on admission were predefined confounders. 
our study include the paucity of data on the smoking status and history of respiratory disease prior to admission, the bilirubin and $\mathrm{Hb}$ levels, the inhaled oxygen concentration during the course of the admission and the hospital outcome following ICU discharge. We acknowledge that these limitations need to be taken into account when interpreting our results. Arguably, a strong correlation between arterial $\mathrm{COHb}$, exhaled carbon monoxide (eCO) and total serum bilirubin as indices of heme metabolism exists in critically ill patients [25]; therefore, we would like to suggest that the absence of bilirubin levels does not hamper the quality of our data. On the other hand, we take into account that the lack of data on smoking status might represent a bias in our study. Current smokers have approximately five-fold higher $\mathrm{COHb}$ levels than the observed average $\mathrm{COHb}$ levels in our study [6]. Of interest, very few of our patients had $\mathrm{COHb}$ levels above $2.5 \%$. We speculate that a considerable amount of the smokers' $\mathrm{CO}$ has been washed out prior to admission to the ICU as the state of their illness did not allow them to smoke in the hours prior to the admission.

Overall, it remains unclear whether there is an actual causal effect of $\mathrm{COHb}$ levels on survival. The antiinflammatory products of $\mathrm{HO}-1$ induction might be beneficial [26]. Failure to activate protective systems including $\mathrm{HO}-1$ in the face of inflammatory conditions may be deleterious. Indeed, variants of the promoter region of the HO-1 gene with an increased activity were recently found to be associated with a reduced risk for the development of adult respiratory distress syndrome [27].

The observed differences in $\mathrm{COHb}$ levels between survivors and non-survivors in our study were statistically significant and indicate that this may be an important pathway. On the other hand, given the relative minuteness of the differences in $\mathrm{COHb}$ between the two groups, we have to conclude that $\mathrm{COHb}$ does not qualify as a predictive marker for ICU mortality. Nevertheless, we hope that the presented data add to a more complete understanding of the characteristics of $\mathrm{COHb}$ in medical intensive care patients.

\section{Conclusion}

Critically ill patients surviving the admission to a medical ICU had slightly higher minimum and marginally higher average $\mathrm{COHb}$ levels when compared to non-survivors. Observed margins were minute and do not qualify $\mathrm{COHb}$ as a marker for ICU mortality.

\section{Key messages}

- Non-surgical patients surviving critical illness had slightly higher minimum and marginally higher average $\mathrm{COHb}$ levels compared to patients who died.
- Observed margins were minute and would not qualify $\mathrm{COHb}$ as a marker for ICU mortality.

\section{Abbreviations}

$\mathrm{CO}$, carbon monoxide; $\mathrm{COHb}$, carboxyhemoglobin; $\mathrm{COPD}$, chronic obstructive pulmonary disease; eCO, exhaled carbon monoxide; $\mathrm{HO}$, heme oxygenase (including isoforms HO-1, HO-2); SAPS II, Simplified Acute Physiology Score version II; SOFA, Sepsis-related Organ Failure Assessment.

\section{Author details}

'Department of Respiratory and Critical Care Medicine, Otto Wagner Hospital, Sanatoriumstrasse 2, A-1140 Vienna, Austria. 'Ludwig Boltzmann Institute for Chronic Obstructive Pulmonary Disease and Pneumologic Epidemiology, Otto Wagner Hospital, Sanatoriumstrasse 2, A-1140 Vienna, Austria. ${ }^{3}$ Department of Internal Medicine III, Gastroenterology and Hepatology, General Hospital Vienna, Währinger Gürtel 18-20, 1090 Vienna, Austria.

\section{Authors' contributions}

ASF drafted the manuscript; MW and CZ critically revised the manuscript; GCF was responsible for the conception and design of the study and carried out the statistical analysis. All authors read and approved the final version of the manuscript.

\section{Competing interests}

The authors declare that they have no competing interests.

Received: 8 May 2011 Revised: 24 August 2011

Accepted: 11 January 2012 Published: 11 January 2012

\section{References}

1. Li L, Hsu A, Moore PK: Actions and interactions of nitric oxide, carbon monoxide and hydrogen sulphide in the cardiovascular system and in inflammation - a tale of three gases! Pharmacol Ther 2009, 123:386-400.

2. Wu L, Wang R: Carbon monoxide: endogenous production, physiological functions, and pharmacological applications. Pharmacol Rev 2005, 57:585-630.

3. Tenhunen R, Marver HS, Schmid R: The enzymatic conversion of heme to bilirubin by microsomal heme oxygenase. Proc Natl Acad Sci USA 1968, 61:748-755.

4. Berk PD, Blaschke TF, Scharschmidt BF, Waggoner JG, Berlin NI: A new approach to quantitation of the various sources of bilrubin in man. J Lab Clin Med 1976, 87:767-780.

5. Coburn RF, Forster RE, Kane PB: Considerations of the physiological variables that determine the blood carboxyhemoglobin concentration in man. J Clin Invest 1965, 44:1899-1910.

6. Hart CL, Smith GD, Hole DJ, Hawthorne VM: Carboxyhaemoglobin concentration, smoking habit, and mortality in 25 years in the Renfrew/ Paisley prospective cohort study. Heart 2006, 92:321-324.

7. Fenn WO: The burning of CO in tissues. Ann N Y Acad Sci 1970, 174:64-71.

8. Maines MD, Trakshel GM, Kutty RK: Characterization of two constitutive forms of rat liver microsomal heme oxygenase. Only one molecular species of the enzyme is inducible. J Biol Chem 1968, 261:411-419.

9. Elbirt KK, Whitmarsh AJ, Davis RJ, Bonkovsky HL: Mechanism of sodium arsenite-mediated induction of heme oxygenase- 1 in hepatoma cells. Role of mitogen-activated protein kinases. J Biol Chem 1998, 273:8922-8931.

10. Coburn RF, Williams WJ, Forster RE: Effect of Erythrocyte Destruction On Carbon Monoxide Production In Man. J Clin Invest 1964, 43:1098-1103.

11. Maines MD: The heme oxygenase system: a regulator of second messenger gases. Annu Rev Pharmacol Toxicol 1997, 37:517-554.

12. Mumby S, Upton RL, Chen Y, Stanford SJ, Quinlan GJ, Nicholson AG, Gutteridge JM, Lamb NJ, Evans TW: Lung heme oxygenase-1 is elevated in acute respiratory distress syndrome. Crit Care Med 2004, 32:1130-1135.

13. Yasuda H, Yamaya M, Yanai M, Ohrui T, Sasaki H: Increased blood carboxyhaemoglobin concentrations in inflammatory pulmonary diseases. Thorax 2002, 57:779-783.

14. Yasuda H, Yamaya M, Nakayama K, Ebihara S, Sasaki T, Okinaga S, Inoue D, Asada M, Nemoto M, Sasaki H: Increased arterial carboxyhemoglobin 
concentrations in chronic obstructive pulmonary disease. Am J Respir Crit Care Med 2005, 171:1246-1251.

15. Baranano DE, Rao M, Ferris CD, Snyder SH: Biliverdin reductase: a major physiologic cytoprotectant. Proc Natl Acad Sci USA 2002, 99:16093-16098.

16. Ryter SW, Otterbein LE: Carbon monoxide in biology and medicine. Bioessays 2004, 26:270-280.

17. Suttner DM, Dennery PA: Reversal of HO-1 related cytoprotection with increased expression is due to reactive iron. FASEB J 1999, 13:1800-1809.

18. Melley DD, Finney SJ, Elia A, Lagan AL, Quinlan GJ, Evans TW: Arterial carboxyhemoglobin level and outcome in critically ill patients. Crit Care Med 2007, 35:1882-1887.

19. Motterlini R, Otterbein LE: The therapeutic potential of carbon monoxide. Nat Rev Drug Discov 2010, 9:728-743.

20. Allred EN, Bleecker ER, Chaitman BR, Dahms TE, Gottlieb SO, Hackney JD, Pagano M, Selvester RH, Walden SM, Warren J: Short-term effects of carbon monoxide exposure on the exercise performance of subjects with coronary artery disease. N Engl J Med 1989, 321:1426-1432.

21. Kleinman MT, Davidson DM, Vandagriff RB, Caiozzo VJ, Whittenberger JL: Effects of short-term exposure to carbon monoxide in subjects with coronary artery disease. Arch Environ Health 1989, 44:361-369.

22. Metnitz PG, Steltzer H, Popow C, Valentin A, Neumark J, Sagmüller G, Schwameis F, Urschitz M, Mühlbacher F, Hiesmayr M, Lenz K: Definition and evaluation of a documentation standard for intensive care medicine: the ASDI (Working Group for Standardization of a documentation system for intensive care medicine) pilot project. Wien Klin Wochenschr 1997, 109:132-138.

23. Le Gall JR, Lemeshow S, Saulnier F: A new Simplified Acute Physiology Score (SAPS II) based on a European/North American multicenter study. JAMA 1993, 270:2957-2963.

24. Vincent JL, Moreno R, Takala J, Willatts S, De Mendonça A, Bruining H, Reinhart CK, Suter PM, Thijs LG: The SOFA (Sepsis-related Organ Failure Assessment) score to describe organ dysfunction/failure. On behalf of the Working Group on Sepsis-Related Problems of the European Society of Intensive Care Medicine. Intensive Care Med 1996, 22:707-10.

25. Morimatsu H, Takahashi T, Maeshima K, Inoue K, Kawakami T, Shimizu H, Takeuchi M, Yokoyama M, Katayama H, Morita K: Increased heme catabolism in critically ill patients: correlation among exhaled carbon monoxide, arterial carboxyhemoglobin, and serum bilirubin IXalpha concentrations. Am J Physiol Lung Cell Mol Physiol 2006, 290:L114-L119.

26. Ryter SW, Alam J, Choi AM: Heme oxygenase-1/carbon monoxide: from basic science to therapeutic applications. Physiol Rev 2006, 86:583-650.

27. Sheu CC, Zhai R, Wang Z, Gong MN, Tejera P, Chen F, Su L, Thompson BT, Christiani DC: Heme oxygenase-1 microsatellite polymorphism and haplotypes are associated with the development of acute respiratory distress syndrome. Intensive Care Med 2009, 35:1343-1351.

doi:10.1186/cc11138

Cite this article as: Fazekas et al: Carboxyhemoglobin levels in medical intensive care patients: a retrospective, observational study. Critical Care 2012 16:R6.

\section{Submit your next manuscript to BioMed Central and take full advantage of:}

- Convenient online submission

- Thorough peer review

- No space constraints or color figure charges

- Immediate publication on acceptance

- Inclusion in PubMed, CAS, Scopus and Google Scholar

- Research which is freely available for redistribution 